\title{
Reflexo da interação genótipo $x$ ambiente sobre o melhoramento genético de feijão
}

\section{Reflex of genotype $x$ environment interaction on the genetic improvement of bean}

\author{
Thayse Cristine Vieira Pereira ${ }^{\mathrm{I}^{*}}$ Rodolfo Schmit $^{\mathrm{I}}$ Eduardo José Haveroth $^{\mathrm{I}}$ Rita Carolina de Melo ${ }^{\mathrm{I}}$

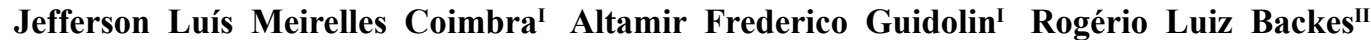

RESUMO

O objetivo foi avaliar os componentes da variância fenotipica e estimar a influência da interação genótipo* *ambiente no rendimento de grãos em feijão. Os componentes da variância fenotípica foram estimados pelo método da máxima verossimilhança restrita e do melhor preditor linear não viesado (REML/BLUP), juntamente com o espaço de inferência específico. As avaliações foram realizadas nas safras agrícolas de 2006/07 a 2011/12 no município de Lages/ SC. Durante o periodo, 104 genótipos foram avaliados. Os dados são desbalanceados, sendo que 13 genótipos permaneceram nos ensaios em todos os anos. Observando os resultados, foi possivel visualizar que a grande variação (59,0\%) no comportamento dos genótipos ao longo dos anos é atribuída principalmente à variância do ambiente $\left(\sigma^{2}=436.245\right)$. Houve diferença significativa entre genótipos para todos os ambientes. Porém, a diferença entre eles foi constante, ou seja, os genótipos não responderam de modo diferenciado frente aos ambientes. A interação genótipo*ambiente $\left(\sigma_{g a}^{2}=1.368\right)$ responde preponderantemente por uma ínfima alteração $(0,2 \%)$ na variação fenotípica, não discriminando de genótipos de feijão quanto ao rendimento de grãos em Lages/SC. Este fato favorece programas de melhoramento vegetal, onde a interação genótipo*ambiente poderia dificultar a distinção, seleção e recomendação de constituições genotípicas superiores. Nessa situação, processos de recomendação de cultivares (ensaio de valor de cultivo e uso - VCU) que mantenham os mesmos genótipos dispensam avaliações sucessivas, pois o ranqueamento é paralelo no decorrer dos anos.

Palavras-chave: efeito do ambiente, melhoramento vegetal, modelos lineares mistos, Phaseolus vulgaris L., $R E M L / B L U P$.

\section{ABSTRACT}

The objective of this research was to evaluate the phenotypic variance components and estimate the influence of interaction genotype*environment in grain yield of beans. The variance components were estimated by the method restricted maximum likelihood and best linear unbiased prediction (REML / BLUP), along with the specific space of inference. Data were collected during the crop seasons 2006/07 to 2011/12 in Lages, SC - Brazil. During this period, 104 genotypes were evaluated. The data are unbalanced and 13 genotypes remained presents in all the assays years. Observing the results it was possible to see that the large variation (59.0\%) in the performance of genotypes over the years is primarily attributable to the variance of the environment ( $\sigma 2 a=436245)$. There were significant differences among genotypes for all environments, but the difference between them were constant, ie, the genotypes did not respond differently in environments. Genotype*environment responds primarily by very small changes $(0.2 \%)$ in the phenotypic variation $(\sigma 2 g a=1368)$, with no parameters to discriminate the grain yield of genotypes in Lages, SC - Brazil. This fact makes easier the selection in plant breeding programs, where interaction genotype*environment could hinder distinction and selection of superior genotypic constitutions. In this situation, the processes of recommendation from improved lines (assay value for cultivation and use - VCU) that maintain the same genotypes dispense successive evaluations, since the ranking is parallel over the years.

Key words: effect of the environment, plant improvement, linear mixed models, Phaseolus vulgaris L., REML / BLUP.

\section{INTRODUÇÃO}

Frequentemente, o resultado obtido na lavoura de feijão é uma produtividade média de grãos instável ao longo dos anos (COIMBRA

IPrograma de Pós-graduação em Ciências Agrárias, Departamento de Agronomia, Instituto de Melhoramento e Genética Molecular da UDESC (IMEGEM), Universidade do Estado de Santa Catarina (UDESC), Av. Camões, 2090, Conta Dinheiro, 88520-000, Lages, SC, Brasil. E-mail: thayseagro@gmail.com. *Autor para correspondência.

IIDepartamento de Fitotecnia, Universidade Federal de Santa Maria (UFSM), Santa Maria, RS, Brasil. 
et al., 2009). Os modelos climáticos recentes preveem a diminuição ou estagnação dos recursos agrícolas, assim o aumento na produção é cada vez mais dependente do incremento no rendimento de grãos em sistemas agrícolas eficientes (MBA et al., 2012). O rendimento de grãos é um caráter poligênico e sofre forte influência do ambiente na expressão do fenótipo.

O melhorista busca genótipos com maior valor genotípico em relação aos valores de ambiente e da interação genótipo*ambiente $\left(\mathrm{G}^{*} \mathrm{~A}\right)$ ou aqueles que agreguem todos os componentes fenotípicos positivos. O efeito da interação $\mathrm{G}^{*} \mathrm{~A}$ pode tornar a seleção e recomendação de genótipos onerosa e lenta, mesmo quando os genótipos apresentam características promissoras, pois proporciona alteração no desempenho relativo dos genótipos em virtude da diferença de ambiente (CARVALHO et al., 2002).

$\mathrm{O}$ uso de procedimentos genético estatísticos mais refinados, como a metodologia de modelos lineares mistos, é uma tendência no melhoramento de plantas (PIMENTEL et al., 2014). Essa metodologia fornece parâmetros adicionais relevantes para identificação de constituições genotípicas superiores (RAMALHO \& ARAÚJO, 2011; FREITAS et al., 2013). Pode ser obtida uma informação pormenorizada quando são avaliados os efeitos de ambiente e da interação $\mathrm{G}^{*}$ A pelo melhor preditor linear não viesado (Best Linear Unbiased Prediction - BLUP), juntamente com o efeito simples dos genótipos (LITTELL et al., 2006). A metodologia proporciona considerável benefício na obtenção do valor genotípico e das médias incondicionais $(X \beta+Z v)$, as quais são bem mais requintadas do que as médias condicionais $(X \beta)$. As estimativas geradas são mais confiáveis, ou seja, possuem um desvio padrão menor (MCLEAN et al., 1991; PIEPHO, 1994).

Assim, o objetivo foi avaliar os componentes da variância fenotípica e estimar a influência da interação genótipo*ambiente no rendimento de grãos de feijão.

\section{MATERIAL E MÉTODOS}

Os dados experimentais relativos ao caráter rendimento de grãos $\left(\mathrm{kg} \mathrm{ha}^{-1}\right)$ são provenientes dos ensaios de Valor de Cultivo e Uso em Feijão, coordenados pela Empresa de Pesquisa Agropecuária e Extensão Rural de Santa Catarina (EPAGRI), de Chapecó, Santa Catarina. Todos os ensaios foram conduzidos na área experimental do
Instituto de Melhoramento e Genética Molecular da UDESC (IMEGEM) em Lages/SC, no planalto serrano catarinense $\left(27^{\circ} 48^{\prime} \mathrm{S}, 50^{\circ} 19^{\prime} \mathrm{O}\right.$ e $920 \mathrm{~m}$ de altitude), durante os anos agrícolas 2006/07, 2007/08, 2008/09, 2009/10, 2010/11, 2011/12. O delineamento experimental utilizado foi de blocos completamente casualizados com quatro repetições por tratamento. A unidade experimental foi composta por quatro linhas de quatro metros, com espaçamento uniforme entre linhas e densidade de semeadura de 15 sementes viáveis por metro linear, visando população final de 200.000 plantas por hectare. A parcela útil foi composta pelas duas linhas centrais, excluindo $0,5 \mathrm{~m}$ de bordadura. As adubações de semeadura e de cobertura foram realizadas de acordo com as recomendações técnicas para a cultura.

Foram avaliados anualmente 24 genótipos no Ensaio Estadual de Linhagens e de Cultivares de Feijão e 20 genótipos no Ensaio Sul Brasileiro de Valor de Cultivo e Uso em Feijão, totalizando 104 genótipos avaliados no período. Os dados são desbalanceados, sendo que 13 genótipos permaneceram nos ensaios em todo o período avaliado. A homogeneidade de variância e a normalidade dos dados foram verificadas por meio dos testes estatísticos de Levene e ShapiroWilk, respectivamente. O rendimento de grãos dos genótipos avaliados nos respectivos ambientes foi comparado pela probabilidade em $\mathrm{F}$ a $5 \%$ de significância, de acordo com as funções testadas, combinando sempre o mesmo genótipo em todos os pares de ambientes possíveis.

A análise de variância é dada por: $y_{i j}=\mu+g_{i} \mid \varphi_{j}+\tau_{j}+u_{j}+e_{i j r}$, onde os termos descritos são: $y_{i j r}=$ rendimento de grãos do i-ésimo genótipo no j-ésimo ambiente na r-ésima repetição $(i=1, \ldots, G ; j=1, \ldots, E ; r=1, \ldots, R), \mu=$ média geral (efeito fixo), $g_{i}=$ efeito do i-ésimo genótipo (efeito fixo), $\varphi_{i j}=$ efeito de bloco do i-ésimo genótipo no j-ésimo ambiente (efeito aleatório), $\tau_{j}=$ efeito do j-ésimo ambiente (efeito aleatório), $u_{i j}=$ interação do i-ésimo genótipo com j-ésimo ambiente (efeito aleatório), e $e_{i j r}=$ resíduo (efeito aleatório).

O método utilizado foi o da máxima verossimilhança restrita (REML/BLUP), que, sob modelo individual, tornou-se o método padrão para a estimativa de componentes de variância e parâmetros genéticos, preferencialmente quando obtidos a partir de dados desbalanceados (SPILKE et al., 2005). A opção por esse método decorre de suas propriedades estatísticas, superiores às propriedades dos estimadores de quadrados 
mínimos e de máxima verossimilhança (SEARLE et al., 1992). Dessa forma, é possível trabalhar com um grande número de dados, ainda que os dados sejam desbalanceados, sem que os resultados obtidos na análise tenham prejuízo.

\section{RESULTADOS E DISCUSSÃO}

$\mathrm{Na}$ tabela 1, podem ser observados os componentes da variância fenotípica em feijão, obtidos para o caráter rendimento de grãos. $\mathrm{Na}$ análise desses componentes, foi possível visualizar que a grande variação entre as médias marginais dos genótipos deve ser atribuída à variância do ambiente $\left(\sigma_{a}^{2}=436.245\right)$, o que corresponde a $59,0 \%$ da variação total obtida dos efeitos aleatórios. De modo contrário, a interação $\mathrm{G}^{*} \mathrm{~A}\left(\sigma_{\mathrm{ga}}^{2}=1.368\right)$ responde preponderantemente por uma ínfima alteração $(0,2 \%)$ na variação fenotípica.

A predição de valores genéticos, os métodos de seleção e recomendação de genótipos superiores dependem, essencialmente, da estimativa dos componentes da variância (SEARLE et al., 1992; SMITH et al., 2001). Vários autores (BORGES et al.,2010; CARVALHO et al., 2002; BURGUEÑO et al., 2008; COIMBRA et al., 2008; PHIEPO et al., 2012) já demonstraram que as maiores fontes de variação em caracteres de herança quantitativa são devidas aos fatores de ambiente e da interação $G^{*} A$ quase que integralmente. Mostrando assim que a inferência extraída para este tipo de caráter por meio do fenótipo não é um bom indicador do genótipo (PIEPHO, 2000). Quantificando os componentes da variância fenotípica, pode ser avaliada a viabilidade de programas de melhoramento vegetal, a sensibilidade genotípica, além de prever ganhos na seleção e recomendação de constituições genotípicas superiores. Dessa maneira, pode-se optar por estratégias que maximizem os ganhos genéticos, sem onerar ainda mais os programas de melhoramento.
O valor fenotípico dos genótipos avaliados no decorrer dos anos teve comportamento similar. A tabela 2 apresenta o valor do efeito genotípico $(\mathrm{g})$ e também o valor genotípico $(\mu+\mathrm{g})$ de cada genótipo que se manteve nos ensaios durante todo o período avaliado. A amplitude (2388-1757) entre os valores genotípicos obtidos está ligada à variabilidade genética existente $(\mu=1848)$. O feijão é uma espécie autógama, não possuindo atualmente tecnologia para comercialização de híbridos. Todos os genótipos avaliados nos ensaios de VCU são linhagens em estágio avançado de homozigoze, logo a hipótese de variância genética é descartada, sendo adotados como fatores fixos no modelo. Assim os genótipos não são uma amostra aleatória de uma população definida, como seria de obter, por exemplo, na pesquisa de amostragem, porque os genótipos no ensaio são o resultado de seleção com esforço considerável (PHIEPO et al., 2008).

As cultivares de feijão semeadas no Brasil apresentam uma base genética muito estreita, o que é comum entre variedades comerciais (VIEIRA et al., 2001). Essa restrição é imposta tanto pelo agricultor quanto pelo consumidor, pois toda a cadeia produtiva do feijão tem preferência por um ideótipo de grão e planta determinado, representando, assim, um gargalo na variabilidade genética dessa cultura (COIMBRA et al., 2009). A abordagem de modelos lineares mistos mostra-se, portanto, coerente com a realidade. Os resultados obtidos estão de acordo com os relatos de PIEPHO \& MÖHRING (2005), que descreveram a abordagem do REML/BLUP como conceitualmente mais completa e muito mais informativa.

A ampla contribuição dos ambientes na variância fenotípica é mostrada na tabela 3 . O primeiro ano agrícola (2006/2007) apresentou maior valor de predição $742 \mathrm{~kg} \mathrm{ha}^{-1}$, sendo que, neste ano, as condições climáticas foram favoráveis para o desenvolvimento da cultura (temperaturas uniformes e chuvas espaçadas), proporcionando a maior produtividade média do período avaliado

Tabela 1 - Predição dos componentes da variância fenotípica pelo REML/BLUP para o caráter rendimento de grãos em feijão avaliados em ensaios de valor de cultivo e uso (VCU) em seis diferentes anos no planalto serrano. UDESC-IMEGEM. Lages, SC. 2015.

\begin{tabular}{lccc}
\hline Componentes da Variância & Estimativa & Erro padrão & \% total variação \\
\hline Bloco & 13.081 & 11.602 & 1,7 \\
Ano & 436.245 & 276.670 & 59,0 \\
Ano*Genótipo & 1.368 & 9.226 & 0,2 \\
Resíduo & 288.317 & 14.608 & 39,0 \\
\hline
\end{tabular}

Ciência Rural, v.46, n.3, mar, 2016. 
Tabela 2 - Valor genotípico $(\mu+\mathrm{g})$ e efeito genotípico $(\mathrm{g})$ estimado para o caráter rendimento de grãos pertencentes aos 13 genótipos de feijão avaliados em seis anos agrícolas no ensaio de valor de cultivo e uso (VCU), no planalto serrano. IMEGEM-UDESC. Lages, SC, 2015.

\begin{tabular}{lcc}
\hline Genótipo & Valor genotípico & Efeito genotípico \\
\hline 01 & 2388 & 540 \\
03 & 2214 & 374 \\
05 & 2136 & 288 \\
06 & 1757 & -90 \\
56 & 2085 & 237 \\
60 & 2154 & 306 \\
61 & 1806 & -41 \\
71 & 2187 & 339 \\
72 & 2268 & 420 \\
73 & 2012 & 164 \\
77 & 2112 & 264 \\
85 & 2069 & 221 \\
87 & 2229 & 381 \\
\hline
\end{tabular}

$2727 \mathrm{~kg} \mathrm{ha}^{-1}$. Destarte, o ano 2010/2011 deslocou negativamente a média geral de produção, com predição de $-1075 \mathrm{~kg} \mathrm{ha}^{-1}$. O ano agrícola 2010/2011 foi considerado um ano atípico, com alto volume de precipitação por um longo período, apresentando a menor produtividade média do período avaliado: $986 \mathrm{~kg} \mathrm{ha}^{-1}$. Os ambientes (anos) testados foram considerados como amostra aleatória de uma população de ambientes (PIEPHO et al., 2012). A diferença existente entre a média dos dois ambientes extremos foi de $1741 \mathrm{~kg} \mathrm{ha}^{-1}$, isso justifica a grande divergência entre os ambientes e a importante influência destes sobre a expressão do caráter.

A variação entre ambientes pode gerar um componente de variância muito maior em relação aos demais componentes considerados especificamente no melhoramento de plantas, tornando esse fator de grande importância para entendimento das variações globais das médias (RESENDE, 2002). O uso do REML/BLUP possibilita, em termos práticos, compreender quais as causas de variação que compõem a variação total observada por meio do fenótipo (RESENDE \& BARBOSA, 2006). Desse modo, compreende-se a limitação inerente que os métodos que estimam a estabilidade fenotípica (EBERHART \& RUSSEL, 1966; WRICKE, \& WEBER, 1986) estão sujeitos, pois não conseguem isolar estes efeitos efetivamente.

A figura 1 demonstra a ampla variação obtida nas funções estimadas para o mesmo genótipo em cada par de ambientes específico, evidenciando o potencial da variação referente ao ano e à sensibilidade das constituições genotípicas, mediante as condições ambientais distintas. Essa instabilidade mostra que os genótipos respondem ao ambiente, isto é, o desempenho é proporcional às melhorias de ambiente.

Analisando os gráficos da figura 1, observa-se que todos os genótipos tiveram a mesma tendência de comportamento conforme a mudança de ambiente. O efeito da interação $G^{*} A$, embora existente, mostrou pequena contribuição no rendimento de grãos. A variação no fenótipo, que é devida à interação $\mathrm{G}^{*} \mathrm{~A}$, não é suficiente para discriminá-los. Fracionando eficientemente as causas de variação que compõem o fenótipo, são estimadas com acurácia as causas da verdadeira associação biológica entre o valor fenotípico e o valor genotípico (PIEPHO, 1994; RESENDE \& BARBOSA, 2006). Em programas de melhoramento vegetal, a nulidade da interação $G^{*} A$ favorece a distinção e seleção de constituições genotípicas superiores, sendo que a máxima associação entre a expressão do valor fenotípico e genotípico é obtida com a inexistência da interação genótipo*ambiente.

Em processos de recomendação de cultivares (ensaios de linhagens), como os ensaios de VCU que mantenham os mesmos genótipos, as avaliações sucessivas poderiam ser dispensadas. O ranqueamento genotípico é paralelo no decorrer dos anos, assim os recursos do programa de melhoramento poderiam ser otimizados. Os resultados obtidos neste trabalho estão de acordo com ATROCH et al. (2000) e BORGES et al. (2010), os quais concluíram que a metodologia de modelos mistos é uma estatística de fácil aplicação e de grande utilidade na avaliação de ensaios de valor de cultivo e uso, sobretudo na seleção e no descarte de linhagens a cada ano agrícola.

Tabela 3 - Predição da contribuição de cada ano na expressão do fenótipo para o caráter rendimento de grãos $\left(\mathrm{kg} \mathrm{ha}^{-1}\right)$ em feijão avaliados em ensaios de valor de cultivo e uso (VCU) do planalto serrano. Lages, SC, 2015.

\begin{tabular}{llc}
\hline Ano agrícola & BLUP & Erro padrão \\
\hline $2006 / 07$ & 742 & 274 \\
$2007 / 08$ & 528 & 273 \\
$2008 / 09$ & 132 & 273 \\
$2009 / 10$ & -409 & 273 \\
$2010 / 11$ & -1075 & 274 \\
$2011 / 12$ & 80 & 274 \\
\hline
\end{tabular}




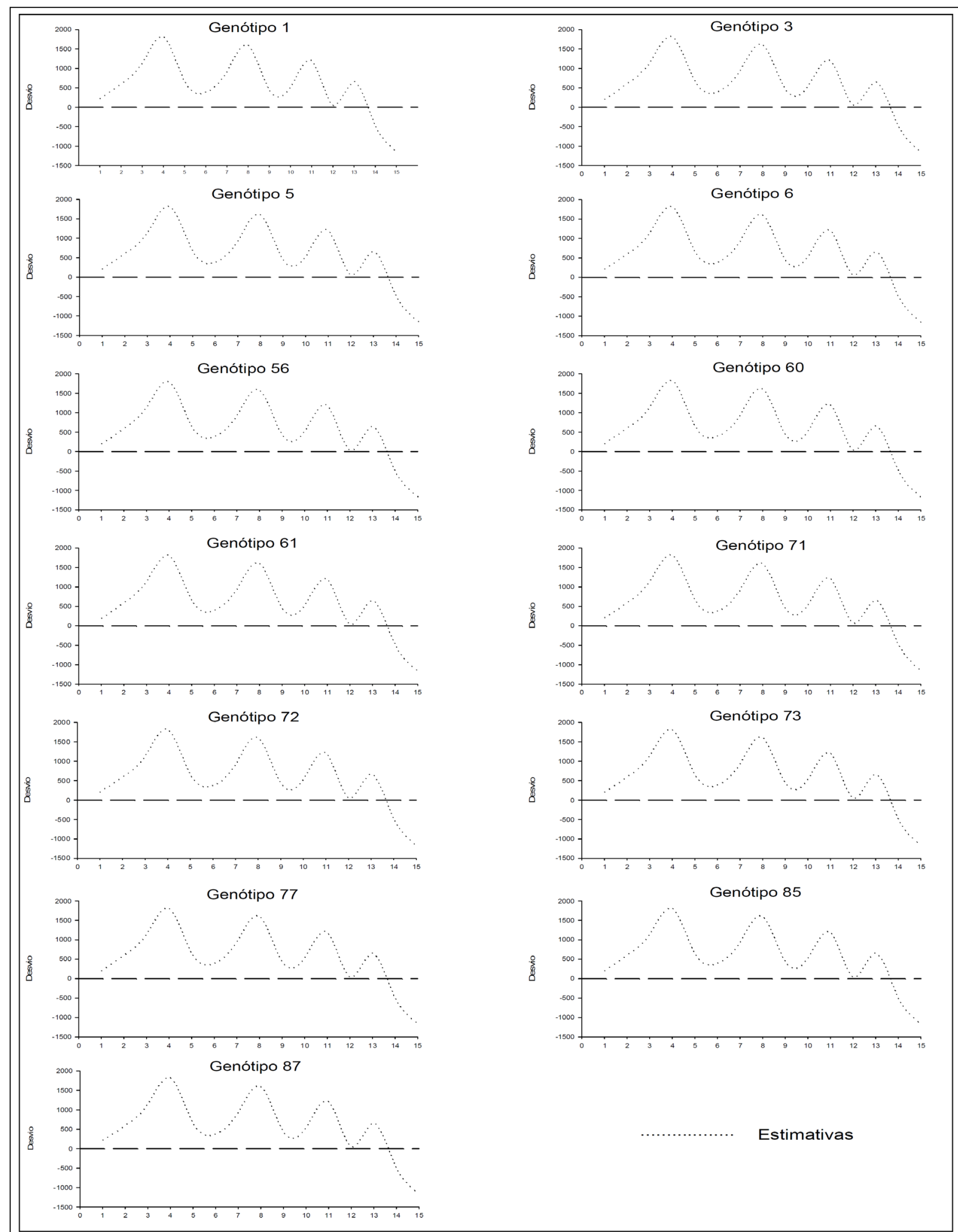

Figura 1 - Desvios do comportamento genotípico conforme espaço de inferência específico. Produtividade de feijão em ensaios de VCU (valor de cultivo e uso) durante as safras agrícolas de 2006/07 a 2011/12 combinados dois a dois: 1=2006/07x2007/08, $2=2006 / 07 \times 2008 / 09,3=2006 / 07 \times 2009 / 10,4=2006 / 07 \times 2010 / 11,5=2006 / 07 \times 2011 / 12,6=2007 / 08 \times 2008 / 09,7=2007 / 08 \times 2009 / 10$, $8=2007 / 08 \times 2010 / 11,9=2007 / 08 \times 2011 / 12,10=2008 / 09 \times 2009 / 10,11=2008 / 09 \times 2010 / 11,12=2008 / 09 \times 2011 / 12,13=2009 / 10 \times 2010 / 11$, 14=2009/10x2011/12, 15=2010/11x2011/12. IMEGEM-UDESC. Lages, SC. 2015.

Ciência Rural, v.46, n.3, mar, 2016. 


\section{CONCLUSÃO}

A interação genótipo*ambiente em Lages/SC responde preponderantemente por uma ínfima alteração na variação fenotípica, não discriminando genótipos de feijão quanto ao rendimento de grãos em Lages/SC. Esse fato favorece programas de melhoramento vegetal, onde a interação genótipo*ambiente poderia dificultar a distinção, seleção e recomendação de constituições genotípicas superiores.

\section{AGRADECIMENTOS}

Agradecemos a Universidade do Estado de Santa Catarina (UDESC), ao Conselho Nacional de Desenvolvimento Científico e Tecnológico (CNPq) e a Fundação de Amparo à Pesquisa e Inovação do Estado de Santa Catarina (FAPESC) pelo apoio financeiro no desenvolvimento deste trabalho.

\section{REFERÊNCIAS}

ATROCH, A. L.; SOARES, A. A.; RAMAlho, M. A. P. Adaptabilidade e estabilidade de linhagens de arroz de sequeiro testadas no Estado de Minas Gerais. Ciência e Agrotecnologia, v. 24, 2000. Disponível em: <http://www.alice.cnptia.embrapa.br/ handle/doc/670530>. Acesso em: 20 nov. 2012

BORGES, V et al. Desempenho genotípico de linhagens de arroz de terras altas utilizando metodologia de modelos mistos. Bragantia v. 69 , n. 4, p. 833-841, 2010. Disponível em: <http://www.scielo. br/pdf/brag/v69n4/v69n4a08.pdf $>$. Acesso em: 25 jan. 2013. doi: 10.1016/S0022-474X(00)00016-3.

BURGUEÑO, J. et al. Using factor analytic models for joining environments and genotypes without crossover genotype $\mathrm{x}$ environment interaction. Crop Science, v.48, p.1291-1305, 2008. Disponível em: <https://dl.sciencesocieties.org/publications/cs/ abstracts/48/4/1291>. Acesso em: 15 jan 2013. doi: 10.2135/ cropsci2007.11.0632.

CARVALHO, C.G.P. et al. Interação genótipo x ambiente no desempenho produtivo da soja no Paraná. Pesquisa Agropecuária Brasileira, v.37, p.989-1000, 2002. Disponível em: <http://www. scielo.br/pdf/pab/v37n7/10803.pdf>. Acesso em: 07 jul 2013.

COIMBRA, J.L.M. et al. Seleção para caracteres adaptativos em acessos de feijão usando REML/BLUP. Magistra, v.20, p.177-185, 2008. Disponível em: <http://link.springer.com/article/10.1007/ s10681-009-0043-0>. Acesso em: 23 jul 2013.

COIMBRA, J.L.M. et al. Mineração da interação genótipo x ambiente em Phaseolus vulgaris L. para o Estado de Santa Catarina. Ciência Rural, v.39, p.355-363, 2009. Disponível em: <http://www.scielo.br/pdf/cr/v39n2/a69cr246.pdf>. Acesso em: 18 out 2013 .

EBERHART, S.A.; RUSSEL, W.A. Stability parameters for comparing varieties. Crop Science, v.6, p.36-40, 1966. Disponível em: <https://dl.sciencesocieties.org/publications/cs/abstracts/6/1/ CS0060010036>. Acesso em: 23 nov 2012. doi: 10.2135/cropscil 966.0011183X000600010011x.
FREITAS, I.L.J. et al. Ganho genético avaliado com índices de seleção e com REML/Blup em milho-pipoca. Pesquisa Agropecuária Brasileira, v.48, n.11, 2013. Disponível em: $<$ http://www.scielo.br/pdf/pab/v48n11/07.pdf>. Acesso em: 05 fev. 2014. doi: 10.1590/S0100-204X2013001100007.

LITTELL, R.C. et al. SAS for mixed models. 3.ed. Cary, NC, 2006. 824 p.

MBA, C. et al. Re-orienting crop improvement for the changing climatic conditions of the 21 Century. Agriculture \& Food Security, v.1, n.7, p.10-23, 2012. Disponível em: <http://www. biomedcentral.com/content/pdf/2048-7010-1-7.pdf $>$. Acesso em: 18 jan. 2013.

McLEAN, R.A. et al. A unified approach to mixed model theory. American Statistician, v.45, n.1, p.54-64, 1991. Disponível em: <http://www.tandfonline.com/doi/abs/10.108 0/00031305.1991.10475767> Acesso em: 28 mar. 2013. doi: $10.1080 / 00031305.1991 .10475767$.

PIEPHO HP et al. The use of two-way linear mixed models in multitreatment meta-analysis. Biometrics, v.68, p.1269-1277, 2012. Disponível em: <http://onlinelibrary.wiley.com/doi/10.1111/ j.1541-0420.2012.01786.x/full>. Acesso em: 13 abr. 2013. doi: 10.1111/j.1541-0420.2012.01786.x.

PIEPHO, H. P. et al. BLUP for phenotypic selection in plant breeding and variety testing. Euphytica, v. 161, n. 1-2, p. 209-228, 2008. Disponível em: <http://link.springer.com/article/10.1007/ s10681-007-9449-8>. Acesso em: 30 out. 2013. doi: 10.1007/ s10681-007-9449-8.

PIEPHO, H.P. Best linear unbiased prediction (BLUP) for regional yield trials: a comparison to additive main effects and multiplicative interaction (AMMI) analysis. Theoretical Applied of Genetics, v.89, n.5, p.647-654, 1994. Disponível em: <http://link.springer.com/article/10.1007/ BF00222462\#page-1>. Acesso em: 07 jul. 2013. doi: 10.1007/ BF00222462.

PIEPHO, H.P. A mixed models approach to mapping quantitative trait loci in barley on the basis of multiple environment data. Genetics, v.156, p.253-260, 2000. Disponível em: $<$ http://www. genetics.org/content/156/4/2043.short>. Acesso em: 30 nov. 2013.

PIEPHO, H.P.; MÖHRING, J. Best linear unbiased prediction of cultivar effects for subdivided target regions. Crop Science, v.45, n.3,p.1151-1159, 2005. Disponivel em: $<$ https://dl.sciencesocieties. org/publications/cs/abstracts/45/3/1151>. Acesso em: 18 fev. 2013. doi: $10.2135 /$ cropsci2004.0398.

PIMENTEL, A.J.B. et al. Estimação de parâmetros genéticos e predição de valor genético aditivo de trigo utilizando modelos mistos. Pesquisa agropecuária Brasileira, v.49, n.11, p.882890, 2014. Disponível em: <http://www.scielo.br/pdf/pab/ v49n11/0100-204X-pab-49-11-00882.pdf>. Acesso em: $25 \mathrm{dez}$. 2014. doi: 10.1590/S0100-204X2014001100007.

RAMALHO, M.A.P.; ARAÚJO, L.C.A.D. Breeding selfpollinated plants. Crop Breeding and Applied Biotechnology, v. 11, n. SPE, p. 1-7, 2011.

RESENDE, M.D.V. Genética biométrica e estatística no melhoramento de plantas perenes. Brasília: Embrapa Informação tecnológica, 2002.975p. 
RESENDE, M.D.V.; BARBOSA, M.H.P. Selection via simulated BLUP based on family genotypic effects in sugarcane. Pesquisa Agropecuária Brasileira, v.41, p.421-429, 2006. Disponível em: <http://www.scielo.br/scielo.php?pid=S0100$204 X 2006000300008 \&$ script $=$ sci_arttext\&tlng=pt $>$. Acesso em: 15 fev. 2014. doi: 10.1590/S0100-204X2006000300008.

SEARLE, S.R. et al. Variance components. New York: J. Wiley, 1992. 528p.

SMITH, A. et al. Analyzing variety by environment data using multiplicative mixed models and adjustments for spatial field trend. Biometrics, v.57, n.4, p.1138-1147, 2001. Disponível em: <http://www.jstor.org/stable/3068246>. Acesso em: 25 mar. 2013.
SPILKE, J. et al. Analysis of unbalanced data by mixed linear models using the Mixed Procedure of the SAS System. Journal Agronomy \& Crop Science, v.191, p.47-54, 2005. Disponivel em: <http:// onlinelibrary.wiley.com/doi/10.1111/j.1439-037X.2004.00120.x/ pdf>. Acesso em: 18 out. 2014. doi: 0931-2250/2005/9101-0047.

VIEIRA, E.S.N. et al. Similaridade genética entre cultivares de feijão do grupo carioca por meio de marcadores moleculares de proteínas e enzimas visando à certificação da pureza genética. Revista Brasileira de Sementes, v.23, p.35-42, 2001. Disponível em: $<$ http://www.abrates.org. br/revista/artigos/2001/v23n2/artigo05.pdf>. Acesso em: 12 jan. 2014.

WRICKE, G.; WEBER, E.W. Quantitative genetics and selection in plant breeding. Berlin: Walter de Druyter, 1986. 406p. 